\title{
DOUGLAS DIEGUES: POESIA E CRISE
}

\author{
Ana Paula Macedo Cartapatti Kaimoti \\ (CAPES/PNPD/UEL)
}

\section{O discurso da crise e a poesia}

Quais os caminhos trilhados pela poesia de Diegues no contexto da literatura brasileira? A singularidade dessa escrita, seu modo de circulação e sua postura diante da tradição literária brasileira fazem com que as respostas a essa pergunta contribuam para a compreensão do discurso da cisma na cena da poesia feita no Brasil, contemporaneamente, considerando esse embaraço a partir da crise que funda a poesia moderna (SISCAR, 2005, 2007).

No contexto do desenvolvimento da sociedade industrial e da racionalidade técnica quea sustenta, sobretudo a partir da segunda metade do século XIX em diante, a constatação da ausência de condições para a existência da poesia é uma reação à lógica da mercadoria e se configura como tema, situação e dispositivo a partir do qual, contraditoriamente, se realiza essa poesia como forma de resistência: "Constatar o fim dos tempos da poesia é um modo de a poesia realizar o espírito moderno" (SISCAR, 2007, p. 178). Em razão disso, segundo Siscar, mais do que um fato, a constatação dessa ausência é o "programa" a partir do qual a poesia passa a existir na modernidade, contra todas as previsões mais catastróficas sobre seu fim, ainda que isso ocorra a partir da incorporação do sentimento trágico de sua impossibilidade: 
A energia de afirmação do heroísmo moderno está diretamente ligada à capacidade que a poesia tem de reconhecer essa crise, ou seja, de reconhecer-se em crise, de reconhecer seu espaço como lugar esvaziado, "marginal", "maldito", em ruínas (SISCAR, 2007, p. 177).

Em terras brasileiras, a recorrência desse discurso faz-se presente de maneiras diferentes e a partir de perspectivas variadas. Contemporaneamente, Siscar identifica um mal-estar que mostra a pertinência da crise para a compreensão das condições em que se pensa e se realiza a poesia no país. Em meados do século XX, esse desconcerto apontou para o cisma entre experiência e experimentação provocado pela proposta da poesia concreta, a partir de outra experiência com o verso, com a forma, que procurava afastar-se do projeto modernista.

Essa divisão torna-se mais evidente com a reação da poesia marginal, logo após, que propunha um caminho oposto, voltado para a comunicação mais direta com o leitor e por um declarado compromisso com o cotidiano que implicou em outras estratégias de circulação de seus textos e numa retomada específica do coloquialismo e do deboche da primeira geração do modernismo brasileiro. Para Siscar, a força desses acontecimentos renovou o discurso da crise na poesia brasileira a ponto de essa herança impor-se às gerações seguintes de maneira embaraçosa:

Esses tremores de terra na série poética, com todas as suas implicações estéticas e ideológicas instauraram uma dissensão a tal ponto contundente que abriu feridas no corpus poético, como se daí em diante não fosse mais possível escrever sem inserir-se em um campo cujas questões já estivessem de antemão colocadas (SISCAR, 2005, p. 4).

No início dos anos 8o, sucessores imediatos dessa cena, Leminski e Ana Cristina César, exemplos elencados pelo autor, assumiram o desafio a partir de dentro de suas obras, com resultados diferentes e produtivos em termos de resposta crítica à cisma mencionada. A poesia dos dois autores já mostra um esgotamento do paradigma mencionado, algo que fica evidente, segundo o autor, no ensaio de Haroldo de Campos sobre a poesia pós-utópica, em 1985.

A partir daí, a crítica tem considerado principalmente a dificuldade da poesia de 90 para cá em apresentar um projeto estético coletivo, destacando o caráter informe e difuso dessa produção, o que para alguns indica um empobrecimento. A ausência de linhas mestras é atribuída frequentemente a uma diversidade de projetos e a uma fragmentação das condições nas quais a poesia se realiza e circula. 
O silêncio de muitos poetas e críticos diante da relação entre essa produção e o cisma da poesia concreta e marginal - como se fosse possível saltar diretamente do modernismo para as portas do século XXI - e a tentativa de desvencilhar-se publicamente dela, são fatores que por si só, de acordo com Siscar, indicam o quanto essa questão é um lugar no qual um modo de relação com o discurso da crise se enuncia e se anuncia e, por essa razão, é um lugar a partir do qual a poesia brasileira mais recente deve ser pensada e melhor compreendida.

\section{Aonde vai a poesia de Douglas Diegues?}

Ainda que longe das grandes editoras e mesmo das menores e mais especializadas em poesia, a obra de Douglas Diegues tem circulado na mídia em suportes variados, por vias incomuns nesse campo de atuação, e por razões que frequentemente se restringem à impressão novidadeira causada pelo registro peculiar de seus textos, escritos em "portunhol selvagem", uma língua inventada na qual se encontram o português, o espanhol, o guarani e o inglês, livremente associados. Junte-se a isso a atitude pública do artista, que lê de maneira performática seus textos híbridos, em tom declamatório e panfletário, e que declara seu lugar de fala fronteiriço, mezzo paraguaio, mezzo brasileiro, aos quatro ventos.

Seja na grande imprensa escrita brasileira, por exemplo, ou em revistas literárias eletrônicas e eventos literários paralelos, essas formas de circulação apresentam-se como parte de um projeto maior que procura, mesmo que inicialmente, burlar as formas tradicionais de legitimação da poesia, o que fica mais evidente nos coletivos editoriais cartoneros dos quais Diegues participa ativamente como editor e autor e no seu blogue, o "Portunhol Selvagem".

A parte disso e em paralelo, sua obra tem chamado mais atenção da academia e foi incluída em pequenas antologias, como a de Moriconi (2008), publicada na Revista Margens/Márgenes, da UFMG, e na revista eletrônica Z Cultural, da UFRJ, e a do mais recente Suplemento Literário da Secretaria de Estado de Cultura de Minas Gerais, em 2013. Além disso, a coleção "Ciranda da poesia" (2012), da editora da UERJ, que trata da poesia contemporânea brasileira, incluiu publicação específica sobre a obra de Diegues, com ensaio de Myriam Ávila e antologia de textos do autor.

Essa atenção não se justifica somente pela tutela tão imediata da militância cultural do poeta, mas pelas particularidades de sua escrita, que procuraremos explorar aqui. Para Moriconi, a escrita de Diegues apresenta uma "prática do poético como prospecção da linguagem", assim 
como os outros textos da coletânea do pesquisador. No caso de Diegues, essa prática expõe uma vertente abusada, paródica e iconoclástica que ironiza a alta cultura com o acréscimo perturbador do portunhol do poeta, que desestabiliza a língua brasileira. Esses aspectos fazem com que sua produção trilhe um caminho paralelo ao tipo de sofisticação erudita dos outros poetas contemporâneos, no quais Moriconi encontra uma desestruturação controlada que reage ao formalismo da maior parte da poesia de 90 com a inclusão, principalmente, da narratividade (MORICONI, 2008, p. 1).

Para Daniel (2008), a poesia de Diegues é excêntrica porque não se vincula à herança imediata da produção poética brasileira, o concretismo e a poesia marginal e a sua relação com ícones do modernismo, como Drummond e Cabral. O hibridismo do portunhol e o caráter periférico e fronteiriço do lócus de enunciação do eu-lírico trazem um alto grau de transgressão e estranhamento aos poemas do autor, que constroem uma terra arrasada, ou de "nadie", metáfora da própria poesia, segundo Daniel.

Por outro lado, Ávila (2012) não localiza explicitamente a obra de Diegues na poesia brasileira recente ou anterior, mas suas observações indicam caminhos nesse sentido, quando explora minuciosamente os recursos poéticos mais recorrentes na produção do autor e traça caminhos possíveis que levam essa ao encontro da poesia de Manoel de Barros, Sousândrade e Oswald de Andrade, inclusive para diferenciá-la dessas referências. Segundo a pesquisadora, essa diferença não se encontra exatamente no portunhol selvagem, mas na maneira como a escrita do autor aproxima a poesia letrada de vertentes da música popular brasileira, como o samba e o repente nordestino, além do rap e do hip hop.

Desse universo, os sonetos, os poemas em prosa e a prosa poética exploram as diversas formas do paralelismo, os refrães, as variações, as anáforas, a fragmentação da parataxe, o ilogismo do nonsense e do non sequitur, recursos a partir dos quais o portunhol selvagem ganha uma dimensão mais complexa, compondo um conjunto heterogêneo que faz mais tensa e grotesca a imagem "urbano-selvática do segundo milênio" construída pelos textos. De acordo com Ávila, por essas razões, a obra do autor "[...] faz convergir em si as linhas de força da 'vida danificada', transformando assim sua poesia em caso exemplar, ícone e avatar dos desenvolvimentos mais recentes" (2012, p. 8).

No espaço das referências locais, a poesia de Diegues faz referência constante a Manoel de Barros e sua lição das coisas, relação presente também em declarações do autor. Nesses depoimentos de Diegues, a selvageria atribuída ao seu projeto estético associa-se a uma noção de primitivismo cara às interpretações da obra em questão. Embora o 
primitivismo de Barros já tenha sido vinculado a um investimento no tipo de retorno crítico às origens que pautou o projeto poético da primeira geração modernista de São Paulo, no Pau-Brasil e na Antropofagia, por exemplo, Siscar (2005) acredita que em Barros esse traço manifesta-se de outro modo, como uma "recuperação ativa de elementos descartados" (p. 6), traço peculiar e excêntrico da poesia brasileira mais recente, possível apenas em razão do esgotamento dos projetos poéticos dos anos 60 e 70, monopolizados pela poesia concreta e pela marginal, seu contraponto.

A partir de referências heterogêneas que associam um regionalismo reinventado, à maneira de Rosa e Cabral, a uma filosofia da linguagem próxima a Rimbaud e Pessoa, a poesia primitiva de Barros, nesse sentido, apresenta uma cumplicidade entre a palavra poética e o insignificante, os restos da cultura e da modernidade técnica, aquilo que é inútil. Essa cumplicidade busca uma infância da linguagem que também apresenta "a origem como um problema” (p. 6-7), questão fulcral da poesia moderna.

Diante da poesia de Diegues, no entanto, esse primitivismo manifestase de outro modo, ainda que resulte, a meu ver, no problema apontado acima. Ambos procuram construir seu discurso sobre a poesia em meio a uma banalidade que tem sentidos diferentes para os dois. Enquanto, em Barros, os elementos insignificantes são frequentemente associados à natureza e a figuras e personagens do cotidiano (insetos miúdos e animais rasteiros, um pente, uma erva daninha, pequenos detritos, mendigos, etc.), reinventados a partir da pequenez daquilo que passa despercebido pelo olhar automatizado pela linguagem prosaica; em Diegues, como bem afirma Ávila (2012), há uma presença mais ostensiva de elementos impregnados pelas relações econômicas, alterados pela condição de mercadoria que determina a condição na qual o eu-lírico se encontra nos poemas do autor de modo totalizante, das quais não há saída possível a não ser por meio de uma exortação retórica quase desesperada.

Tanto na sua obra poética, quanto na sua obra como tradutor das textualidades indígenas, é possível encontrar essa exortação na perspectiva ou projeto a partir do qual o eu-lírico defende a poesia como promessa de felicidade e acesso ao eterno, como um discurso capaz de renovar a experiência do sujeito, retirando-o de sua banalidade, essa última associada ao mundo esvaziado do capitalismo, em sua versão sul-americana ou subalterna. Nesse sentido, essa defesa ocorre principalmente por meio da metáfora do pênis, do sêmen, do esperma - "la leche" ou "la milk" - e do fogo como condição de uma poesia que se declara primitiva, selvagem, e que busca os restos de uma possível autenticidade e/ou originalidade em meio ao mar de mercadorias-fetiche que constituem a cena urbana que seus poemas oferecem. 
A questão do projeto estético do autor é desenvolvida igualmente em textos críticos, como "Douglas Diegues y el portunhol selbagem (3)", no qual afirma e nega o caráter erótico de sua poesia: "Nunca escrevi poemas erótikos. Mas admito o erótiko em mios escritos". No tom confessional que imprime ao texto, sob influência de um relacionamento amoroso, o autor afirma que esse erotismo originou-se de uma produção inicial de poemas "pornoerótikos," escritos com palavras feias e raivosas, da qual logo se cansou, mas que serviram para uma espécie de liberação que o levou para seus textos posteriores, cujas diferenças em relação aos primeiros estão no "amor amor" que, segundo a ambigüidade "pornoerótika" de Diegues, "enfiou nas palabras".

Esse momento coincide com o uso selvagem do portunhol que, longe de fazer do eu-lírico um latin lover devasso, como afirmaram parte daqueles que o criticaram nesse período, ao associar-se ao erotismo, o aproximou da graça perdida das palavras:

Y escrevendo en Portunhol Selvajem eu podia danzar Cumbia como um preso que havia se libertado do português brankelo e oficial. Comecei a escrever coisas que tinham lo erótiko pero tambiém essa graça perdida de los Orígenes. Y kreo ter mi encontrado mais ainda (DIEGUES, 2013).

A busca por essa graça das palavras leva o poeta aos cantos guaranis que traduz para a língua portuguesa e nos quais acredita encontrar o signo da autenticidade, da selvageria, que marca seu projeto estético, irmanando sua retórica ao universo de composição indígena cujo modo de apresentação e inserção no cotidiano das comunidades mostra para o poeta que os guaranis são "os grandes artistas de vanguarda primitiva" da fronteira Brasil-Paraguai-Argentina:

La originalidade, la origem própria, es uma de las marcas registradas del arte Mbyá-Guarani. Cada Mbyá-Guarani es un artista, um artista de la vida, a su manera. [...] Em vez de copiar ellos preferem crear, dar flores, fazer la cousa ao modus Mbyá. [...] vai descobrir que us Mbyá-Guarani ainda non conhecem a linguagem poética porque ellos nunca conheceram outra linguagem que non fosse la linguagem poética (DIEGUES, 2006, p. 3-4).

Nas reflexões de Diegues sobre o primivismo vanguardista da poesia guarani, esse traço é associado a uma relação visceral da arte corporal, verbal, musical e pictórica com os modos de ser da etnia Mbyá. No centro dessa relação, está a palavra, como expressão da vida e da alma, palavraalma encantada cuja manifestação funda a mitologia da própria criação do mundo, sua Kosmofonia: 
A arte da palavra, ou musical, ou ritual, dos Mbyá-Guarani, [...] acontece fora dos limites da arte e se confunde com a própria vida e com a uma religião própria da palavra. Não há distinção entre arte e vida, orar e cantar, dançar e orar e cantar no mundo Mbyá, assim como não há distinção entre palavra e alma (DIEGUES, 2006, p. 13).

Esse trabalho de Diegues ilumina um repertório textual ignorado pela cultura letrada, o das literaturas indígenas sul-americanas, e, mesmo que involuntariamente, participa de um esforço de resistência política e cultural desses povos. Por outro lado, esse trabalho nos interessa aqui, juntamente com seus poemas e poemas em prosa, como lugar de reflexão sobre a escrita do autor e seus impasses. Ao considerar que a poesia Mbyá é verdadeiramente selvagem, seu discurso ainda investe na antiga dicotomia "civilizado-selvagem" que atribuiu aos indígenas um caráter de infância da humanidade e que serviu para variadas formas de dominação no discurso do colonizador.

Por sua vez, como tradutor desses textos de caráter oral para a língua escrita do dominador, o poeta posiciona-se do outro lado, o do civilizado. Contraditoriamente, em sua poesia o uso do portunhol de forma livre, macarrônica, implica um discurso de resistência à tradução no qual Medeiros localiza a selvageria do projeto poético de Diegues. $\mathrm{O}$ problema é que "[...] talvez não se possa ser maximamente 'selvagem' sem tradução, assim como não se pode ser altamente civilizado sem tradução" (MEDEIROS, 2009, p. 142-143).

A contrariedade entre o poeta e o tradutor que afirma a autenticidade natural da poesia indígena sugere que a selvageria anunciada de seus poemas não é verdadeira e espontânea como aquela que vê nos Mbyá, mas, em sua artificialidade, configura-se como um gesto retórico, construído no drama que o poema encena, como podemos observar nos dois poemas a seguir:

Por que escribo?

Escribo para ficar menos mesquinho

belleza de lo invisible

non tem nada a ver com berso certinho

en el culo de qualquer momento

escreber pode ser mais que apenas ir morrendo

la belleza de lo invisible

non se pudre com el tempo

la bosta dos elefantes seca verde clara dura es altamente inflamáble - dá uma llama bem pura nunca se termina de aprender a transformar bosta em luz y otros desenganos - 
178 - Remate de Males 34.1

todos fomos bellos quando teníamos 4 anos

hoje la maioria solo se preocupa com sus narizes

su esperma, su bosta, su lucro, sus missíles (DIEGUES, 2012, p. 70)

burguesa patusca light ciudade morena

el fuego de la palavra vá a incendiar tua frieza

ninguém consigue comprar a sabedoria alegria belleza

vas a aprender agora com cuanto esperma se hace um buen poema

esnobe perua arrogante ciudade morena

tu inteligência burra - oficial - acadêmica - pedante

y tu hipocondríaca hipocrisia brochante

son como um porre de whiski com cibalena

postiza sonriza Barbie bo-ro-co-chô ciudade morena

por que mezquina tanto tanta micharia?

macumba pra turista - arte fotogênica

ya lo ensinaram Oswald - depois Manoel - mas você no aprendeu - son como

desinteria

falsa virgem loca ciudade morena

vas a aprender ahora com quanto esperma se faz um bom poema (DIEGUES, 2003, p. 8)

O primeiro soneto foi incluído tanto na antologia de Moriconi quanto na de Ávila, o segundo, escolha minha que vem de outros trabalhos, foi publicado na obra Dá gusto andar desnudo por estas selvas: sonetos salvages (2003). Ambos partem do modelo shakespeariano, com três quartetos e um dístico final, retomada formal que Moriconi (2008) identifica na poesia brasileira da década de 9o, cujo artificialismo, nesse caso, é associado a uma métrica e a um esquema de rimas irregulares que contribuem para o coloquialismo iconoclasta dos textos.

$\mathrm{O}$ eu-lírico de ambos manifesta-se de maneira ostensiva e exteriorizada, professoral, assumindo o papel do poeta, de acordo com o que Ávila considerou como uma voz cuja subjetividade está toda expressa em seus gestos e ações (2012, p. 8), e falam a um você, também recorrente nos textos do autor. A exploração do recurso da parataxe é reforçada pela ausência de maiúsculas e pontuação, na maior parte dos versos, sobretudo no segundo poema, que investe de maneira mais ostensiva no mergulho do eu-lírico na cena urbana e caótica.

O caráter metalinguístico predomina no primeiro soneto no qual a poesia é o anteparo a um mundo medíocre do qual o poeta, no entanto, retira a matéria de seu trabalho, no caso, os restos, a bosta dos elefantes, com o que se pode fazer a "lama", isto é, a própria poesia, associada a uma série de imagens díspares: ela é "belleza invisible", "llama bem pura", 
"luz" e "desenganos". O dístico final encena sua proposta e cria uma sequência construída por elementos que, não por acaso, fazem parte da mesquinharia da primeira estrofe: sus narizes, sus espermas, su bosta, su lucro, sus missiles.

No segundo soneto, a poesia é também parte de uma retórica de resistência ao artificialismo e ali o poeta-personagem faz sua própria lição. A poesia é "fuego de la palavra", que incendeia, e "esperma", metáforas concentradas na justaposição hiperbólica dos substantivos "sabedoria alegria belleza" que, por sua vez, deve se opor a outras justaposições nas quais a beleza de fato do poema, estranha a suas próprias intenções, é composta pelos signos de uma cidade morena, periférica, fria, materialista, hipócrita, "postiza".

Nesse sentido, os sonetos citados acima mostram o quanto o artifício da linguagem é dispositivo fundamental da construção dos poemas e, contraditoriamente, parte da inautenticidade do mundo banal em que o eu-lírico está mergulhado e à qual procura resistir e ensinar sua resistência ao interlocutor. A beleza autêntica que ele postula para a poesia está longe daquilo que o próprio texto oferece, quando despeja sobre o leitor o caráter grotesco e insano de um universo do qual o próprio eu-lírico parece não conseguir sair. Longe de enfraquecer seu texto, essa contradição indica o quanto o interesse pela origem e pelo sentido da palavra poética são centrais na poesia do autor.

Essas questões apresentam-se também em sua poesia em prosa, como no texto "Rei del sêmen", aliadas ao nonsense da expressão reiterada "Nim en la diplomacia hipócrita nim en la hipocrisia diplomática”:

Estoy en Asunción, admirando la kola de las yiyis hermosas que van o vienen por la calle Palma em medio a la penumbra gris helada de las cinco de la tarde. Nim em la hipocrisia diplomatica nim en la diplomacia hipocrita. Estoy en Asunción, mascando hojas de coca que me ha regalado uno de los editores de la anto selvátika, pensando en la yiyi que se alimenta de kosas de plástico, pobrecita, plásticos kolorinches, plásticos negros, plásticos transparentes. Non estoy en la diplomacia hipocrita nim en la hipocrisia diplomatica. Estoy em Asuncion com el porongo bem duro y las bolas um poko doloridas por haber andado assim, todo el dia, com el porongo bien duro. Estoy curtiendo el frio. El frio nunca estuvo tan perfecto. Las yiyis nunca estuvieron tan hermosas. Nim en la hipocrisia diplomática nim en la diplomacia hipocrita. Estoy en Asunción y tengo abundante semen para llenar tu korazón, para fundar una literatura, para non defraudarte beibi, para liberarte del aburrimiento nazi-anti-nazi kapitalista. Estoy en Asuncion, anti-momia, anti-obvio, antinacionalista-ingênuo-ou-non. Nim en la diplomacia hipócrita nim en la hipocrisia diplomática. Estoy en Asunción pero nom quero vencer nim morir nim hacerme la paja (DIEGUES, 2010). 
Em plena calle Palma, em Assunção, o flâneur da "Paraguaylândia" observa "yiyis hermosas" para as quais oferece, em portunhol selvagem, sua autenticidade, "abundante semen para llenar tu korazón, para fundar una literatura, para non defraudarte beibi, para liberarte del aburrimiento nazi-anti-nazi kapitalista". Essa voz opõe-se a uma "diplomacia hipócrita" e a uma "hipocrisia diplomática", remetendo provavelmente aos encontros entre os presidentes do Paraguai e do Brasil, ocorridos em Ponta Porã e Pedro Juan Caballero por conta de uma crise que envolve tráfico de drogas e disputa de terras na fronteira entre os dois países, encontros cujo caráter oficial, institucional, é imediatamente identificado com o signo da mentira e do engano, da ausência de autenticidade: apenas o flâneur, mastigando suas folhas de coca, é capaz de compreender, de traduzir, a verdadeira - autêntica - situação paraguaia e fronteiriça?

Na poesia em versos livres de Diegues, Ávila identifica uma mudança em relação ao tom retórico e à exterioridade do eu-lírico que predomina nos sonetos, a partir da qual esse sujeito quase desaparece, sufocado por justaposições soltas, fragmentadas e incoerentes de flashes urbanos, midiáticos e violentos. Essa mudança provoca uma diminuição da força da retórica professoral ou profética, como menciona a pesquisadora (a jeremíada de Diegues), nos poemas livres do autor, no quais também observamos a presença de um tom melancólico, a partir do qual o discurso da palavra-esperma quase se desencanta.

No poema em versos livres abaixo, "Damasco", no entanto, essa diminuição e seu caráter melancólico convivem com a presença ainda importante do sujeito enunciador cujo tom profético volta-se para si mesmo, em caráter de urgência, traço também recorrente na poesia de Diegues:

\author{
Llegarei a Damasco \\ antes que amanezca \\ si los aduaneros en Barajas \\ non me mandem voltar a Paraguay \\ Entrarei em Damasco \\ com las próprias pernas \\ Me recusarei a morir de tristeza \\ Patearei la kola del ofizialismo \\ hasta romperla lindamente \\ Beberei el rocio \\ de las flores de las calles \\ y bailarei rayuela cumbia and rockanrroll \\ com la bomboncita mais hermosa de la Babylonia \\ Comerei papas a la huankaina \\ guayabas y pytahaias \\ Inaugurarei el nuebo mundo \\ nel korazon de la lokura
}


Kuando menos se espere

irrumpirá el amanecer que solo yo

y unos pocos amigos y algunas yiyis esperábamos

Never more problemas pelotudos

Never more kachaka dor di cornos

Never more llorikeos

Never more ressaca

Botarei fuego en la literatura

y después salvarei el fuego

Desaparecerei feliz

em medio a la manada di mortos ainda vivos

(DIEGUES, 2013)

Lugar dos afetos e deslocamentos do eu-lírico de Diegues, o Paraguai e Assunção, entre outras localizações, é figura frequente em toda sua poesia. Em "Damasco", o Paraguai é lugar a se evitar, condição da qual se deve fugir em busca da fronteira paradisíaca que também se localiza no Oriente exótico, como a "Pasárgada" de Bandeira. A reiteração dos verbos no futuro do presente no início dos versos dialoga diretamente com esse último texto, posicionando Damasco como um lugar inacessível e utópico que reforça a banalidade do espaço no qual de fato o eu-lírico encontra-se, no presente.

Para fugir dos tristes trópicos em que está mergulhado em meio a mortos ainda vivos, animalizados, esse sujeito deve burlar o controle da fronteira, entrar no paraíso ao modo do contrabando que circula entre Paraguai e Brasil e, dessa maneira, retomar o caminho do colonizador, do explorador do novo mundo, às avessas: "inaugurarei el nuebo mundo nel korazon de la lokura".

Assim, Damasco configura-se como o "lá" invertido do desejo voluntário de exílio do eu-lírico, onde ele vai fundar - inaugurar - sua festa louca, mistura de ritmos diferentes, cumbia e rockanroll, e de bebidas e comidas exóticas, numa cena que se afasta daquela urbe grotesca habitual dos poemas, fazendo dessa cidade fruta, sabor e fuga. Outra referência importante, "O corvo" de Poe, por meio de seu "Never More" reiterado no início dos quatro versos já no final do poema, afasta e ao mesmo tempo nomeia e presentifica aquilo do qual o eu-lírico quer se afastar.

Em paralelo à dicotomia do selvagem e do civilizado do projeto estético do autor, o discurso do colonizador que domina a terra explorada por meio de metáforas edênicas e exóticas apresenta-se no texto como sua prisão de fato. A única fuga possível ocorre por meio do caminho aberto pela palavra-fogo dos versos finais, livre do incêndio pelas mãos do poeta desertor, como literatura renovada e condição para o desaparecimento final do sujeito. Em Damasco, é esse fogo que constrói um paraíso mestiço e estranho com os restos da retórica do dominador. 


\section{A cisma da poesia de Diegues}

Qual a postura da obra de Diegues diante da cisma e do cisma que configuram a crise da poesia brasileira? Buscar essa resposta é procurar como os ritmos da história irrompem na escrita do autor. Nesse sentido, é interessante observar que a crítica da obra do autor desconsiderou essa abordagem. Para Moriconi, as particularidades da obra de Diegues são parte de uma cena atual múltipla de laboratórios poéticos que não se associam a nenhuma corrente estética. Nesse sentido, Daniel recusou a relação da poesia do autor com o cisma deixado pela poesia concreta e pela poesia marginal, considerando sua produção como excêntrica a esse cânone. Por outro lado, a partir de um olhar mais atento às minúcias da composição de Diegues, Ávila trouxe referências do primeiro modernismo e até anteriores para a obra do autor.

Acredito que a instabilidade inerente a essa produção poética abra caminho para todas as abordagens citadas, sendo que nenhuma delas está equivocada. A língua inventada do portunhol selvagem de fato faz do texto de Diegues um corpo estranho, excêntrico no conjunto da poesia atual e refere-se a um processo de experimentação muito específico que não deve seu artificialismo aos experimentos concretos. Há aqui uma busca incessante por burlar o autoritarismo da língua prosaica ao se investir em uma intransitividade complexa que é o de uma língua poética específica.

O primeiro modernismo está presente na retórica dos poemas do autor por meio de referências a Oswald de Andrade e a sua proposta estética, trazidos para dentro do texto, como no caso de um dos sonetos mencionados; além disso, há um sentido antropofágico na maneira como a escrita do autor explora recursos linguísticos, poéticos e musicais variados em sua construção, misturando alta cultura e cultura pop e popular, juntamente com o portunhol selvagem e com o deboche e a ironia do eulírico diante da urbe que o poema descortina.

Ainda assim, é preciso considerar que a preocupação identitária com a nacionalidade, que estava sendo revisada criticamente pelos primeiros modernistas, na poesia de Diegues encontra-se vinculada a uma paisagem fronteiriça e periférica que não reivindica identidade nacional, pelo contrário, desestabiliza identidades no cerne mesmo da escrita do autor, a partir de uma postura mais próxima do sentido do moderno no presente.

Portanto, o aproveitamento dessa herança modernista na obra de Diegues parece estar ligado a sua retórica rebelde, selvagem e antiintelectualista (oficial, acadêmica e pedante), aparentemente aberta à experiência. Esse direcionamento é corroborado pelo coloquialismo desbocado de sua escrita, aliado à incorporação do discurso combativo 
de formas populares como o do rap e da dicção reiterada do repente. Em conjunto, inclusive quanto à referência oswaldiana, esses aspectos apontam para um caminho aberto pela poesia marginal. Algo que se mostra também na busca por modos alternativos de circulação dos textos do autor, em meio digital ou nos livros fabricados artesanalmente com papelão reciclado pelas editoras kartoneras, aspectos que tem algo do tipo de relação mais direta e simples com o leitor que a poesia marginal procurou estabelecer.

Como afirma Ávila, se na poesia de Diegues nada é novo, nada também é imitado. A experiência que sua obra propõe não é um dado pronto, apresenta-se de maneira imprecisa mesmo à revelia das afirmações categóricas da retórica selvagem de sua poesia e de sua atuação como poeta. As contradições entre o artificialismo da fabricação poética de sua escrita e sua reivindicação de autenticidade mostram que o vínculo com o discurso da espontaneidade da poesia marginal não pode ser constatado pacificamente na poesia do autor, questão que se mostra complexa igualmente no próprio âmbito da poesia marginal.

Desse modo, a imagem da "triplefrontera mix" que a obra de Diegues constrói, os recursos que sua escrita mobiliza desde a forma relativamente fixa do soneto à prosa poética, encenam uma discussão sobre o lugar da poesia na contemporaneidade. A postura da obra de Diegues oscila entre uma fé anacrônica na autonomia perdida da poesia e uma escrita na qual esse caráter autônomo afirma-se ao compor sua língua dos signos que ele próprio rejeita: a mercadoria e os restos do capitalismo desenvolvido que são despejados na periferia.

A crise do sentido da poesia, fundadora da modernidade, é parte central da obra do autor e indica que, a despeito de sua retórica da resistência, sua poesia, de fato, tem resistido, a partir de sua capacidade de incorporar ao texto outros ritmos como os da cultura popular, ancestral e midiática e fazer deles sua própria dicção. Como resultado, propõe andamentos diferentes que questionam a existência de um ritmo ou de uma narrativa hegemônica, inserindo-se de modo oblíquo na tradição crítica da poesia moderna.

\section{REFERÊNCIAS BIBLIOGRÁFICAS}

ÁVILA, M. Atenção: Douglas. In: DIEGUES, D. Douglas Diegues: por Myriam Ávila. RJ: EdUERJ, 2012. p. 7-59.

DANIEL, C. Pensando la poesia brasileña em cinco actos. La cabeza del moro, Zacatecas, México, v. 2, n. 11, p. 32-36, abril/jun. 2008. 


$$
184 \text { - Remate de Males } 34.1
$$

DIEGUES, D. Douglas Diegues: por Myriam Ávila. RJ: EdUERJ, 2012.

. Dá gusto andar desnudo por estas selvas: sonetos salvages. Curitiba (PR): Travessa dos editores, 2003.

. Damasco. Disponível em: <http://portunholselvagem.blogspot.com.br/ search?q=damasco $>$. Acesso em: 27 jul. 2013.

. El rey del semen. Disponível em: $<$ http://portunholselvagem.blogspot.com/2010/05/ el-rey-del-semen.html>. Acesso em: 21 maio 2010.

- Douglas Diegues y el portunhol selbagem. Disponível em: <http:// portunholselvagem.blogspot.com.br/2007/03/douglas-diegues-y-el-portunholselbagem.html>. Acesso em: 27 jul. 2013.

MEDEIROS, S. L. R. Os astronautas de Kabakov e Diegues. Itinerários, Araraquara, n.28, p.137-143, Jan./Jun 2009.

MORICONI, I. Poesia oo: nota de apresentação e mini antologia. Revista Margens/ Margenes, n. 9-10, Belo Horizonte, 2008.

SEQUERA, G., DIEGUES, D. (Org.). Kosmofobia Mbya Guarani. São Paulo: Mendonça \& Provazi Editores, 2006.

SISCAR, M.. "Responda, cadáver": o discurso da crise na poesia moderna. Alea, Rio de Janeiro, v. 9, n. 2, Dez. 2007. Disponível em: <http://www.scielo.br/scielo. php?script=sci_arttext\&pid=S1517-106X2007000200003\&lng $=$ en $\&$ nrm $=$ iso $>$. Acesso em: 06 Ag. 2013.

. A cisma da poesia brasileira. Sibila, v.8/9, 2005. Disponível em: http://www. germinaliteratura.com.br/sibila2005_acismadapoesia.htm. Acesso em: 27 jul. 2013. . O discurso da crise e a democracia por vir. In: Poesia e crise: ensaios sobre "a crise da poesia" como topos da modernidade. Campinas: Editora da UNICAMP, 2010. 